\title{
The Impact of the US Election on the US Economy and China's Economy and the Countermeasures
}

\author{
Xiaojuan Xi, Danni Xiao \\ School of Finance, Anhui University of Finance and Economics, Bengbu, China \\ Email:wsfmmwan@163.com
}

How to cite this paper: Xi, X. J., \& Xiao, D. N. (2021). The Impact of the US Election on the US Economy and China's Economy and the Countermeasures. Open Journal of Social Sciences, 9, 517-542.

https://doi.org/10.4236/jss.2021.92034

Received: January 22, 2021

Accepted: February 23, 2021

Published: February 26, 2021

Copyright ( 2021 by author(s) and Scientific Research Publishing Inc. This work is licensed under the Creative Commons Attribution International License (CC BY 4.0).

http://creativecommons.org/licenses/by/4.0/

\section{(c) (i) Open Access}

\begin{abstract}
The US economy and the global economy are affected by the US election. Based on the log-linear model and grey prediction model, this paper quantitatively analyzes the impact of different presidential candidates on the US economy and China's economy. First, we establish a mathematical model and use relevant data to quantitatively analyze the possible impact of different candidates elected on the U.S. economy. Then we establish a mathematical model and use relevant data to quantitatively analyze the possible impact of different candidates elected on China's economy. Finally, we combine these two mathematical models and put forward some suggestions on China's economic countermeasures and policies in the relevant fields under these two situations.
\end{abstract}

\section{Keywords}

Log-Linear Regression, Gray Scale Prediction, Election, Economics; Epidemic Situation

\section{The Introduction of the Case}

2020 is the year of the U.S. presidential election once every four years. Joe Biden, the former vice president who led the Democratic primary, became the Democratic presidential candidate; on the Republican side, the current president Trump won the Republican Party's primary election by a landslide, and had locked in the party's presidential nomination in advance.

The 7-month presidential seesaw ended with more than 270 electoral votes for Democratic presidential candidate Biden.

Although the overall situation has been decided, we are not sure what crazy things Trump will do. However, on November 23, the director of the US General 
Administration informed Biden and his team that the Trump administration was ready to start the process of regime transition. Obviously, Trump also accepted the fact that he was defeated.

Will America change after Biden takes office? How will it change? This is what many people expect, but the answer is complex. It can be expected that the United States will change after Biden takes office. As a senior American politician, Biden will strive to change the United States with his own ideas. There is no doubt about this.

First of all, we should be clear that although Trump and Biden are not one political party, the national strategy of the United States does not originate from a political party, but from the elite consensus of their political and academic circles. The United States' comprehensive suppression of China is the consensus of the national elites. This determines that the general direction of the cooling of Sino-US relations cannot be reversed. After all, the foundation of Sino-US strategic mutual trust has been seriously damaged in the past four years. Although he was once very friendly to China, even if Trump had a strong reputation with China, it was necessary to say that he had been extremely friendly to China.

Second, there are some differences between the Republican Party and the Democratic Party in foreign policy. For example, during the Obama period of the Democratic Party, the United States implemented the Asia Pacific re-balancing strategy and TPP to China, while in the Trump period, it directly withdrew from the TPP, ended the Asia Pacific re-balancing strategy, and fought a trade war and a science and technology war with China. However, the U.S. Democratic Party and the Republican Party have different diplomatic strategies, but the direction of the two parties to contain China has never changed ( $\mathrm{Li} \& \mathrm{Chen}$, 2020).

On this basis, we can see clearly the advantages and disadvantages of Trump and Biden being elected respectively for China. If Trump is elected president of the United States, it is obvious that the current Trump style and strategy will continue. In the next four years, the competition between China and the United States will be more intense, and China will undoubtedly face great pressure, but it is not a bad thing for China.

First, after Trump is elected, he will obviously continue to do his own way, which will make the US influence in international organizations continue to shrink. This is the best time for China to enhance its international influence.

On the other hand, Trump's election will allow China to speed up its investment to make up for its weaknesses. Although it will be more difficult in the short term, such difficulties will make China grow faster. For example, in the field of chips, although Trump's crackdown on China and the containment of Huawei have caused losses to China, China's huge determination and huge human, material and financial resources also mean that China will usher in a period of rapid development in the chip field. In a decade or two, even in the field of chips, China will no longer be inferior to the United States.

If Biden is elected, he will also have his advantages. Because Biden of the 
Democratic Party has a lower line in dealing with people than Trump, Sino-US relations will look friendlier than Trump's government, and there will be a period of recommunication and adjustment between China and the United States, which will not intensify so quickly.

\section{Analysis of the Case}

In order to solve the possible impact of different candidates on the United States and China, and combine them to give China's economy and policies in relevant fields, we make the following analysis to solve these problems.

Step 1: we need to analyze the impact of different candidates on the U.S. economy from the perspective of epidemic response and health insurance policy through the analysis of relevant data.

Step 2: through the analysis of the fluctuation of Shanghai stock index and the change of China's import and export volume on election day, we establish a model to get the influence degree of different candidates on China's economy.

Step 3: combined with the models in question 1 and question 2, we give some suggestions on China's economic development in relevant fields.

\section{Assumptions}

There are many factors that can affect the safety inspection. Our model is built and implemented in a relatively ideal environment. Therefore, we make the following assumptions:

It is assumed that the speeches of the two candidates are not exaggerating and can do what they say;

It is assumed that both of them can carry out the policy smoothly;

It is assumed that the influence of other countries on the two countries is the same as before, and there is no major incident.

\section{Symbol Description}

In the section, we use some symbols for constructing the model as follows, See Table 1.

\section{Problem Analysis and Model Building}

\subsection{Part 1: Impact on the United States}

Problem analysis: after analyzing the policies put forward by different candidates in the propaganda, we found that the policies implemented by them in the aspects of new epidemic situation and medical insurance were the most different. Therefore, we select the new epidemic situation and health insurance to analyze the impact of the election of the two candidates on the U.S. economy.

\subsubsection{Impact of Epidemic Situation \\ 1) Data acquisition}

From the U.S. Department of health and human services website 
(http://www.hhs.gov). To obtain the data of the rate of wearing masks, the average price of new crown detection, the average number of testing centers per state, the total number of epidemic monitoring staff, the number of existing infections and the number of new infections per month during the epidemic period in the United States. Table 2 is as follows:

\section{2) Exploratory analysis}

Data on the period of the outbreak in the United States, See Table 1.

3) Establish a logarithmic linear model

a) Selection of variables

According to the comparison of Trump and Biden's different epidemic prevention measures, some epidemic data collected will have an impact on the U.S. economy. We decided to select the mask wearing rate (MSR), the average new crown detection price (AP), the average number of monitoring centers per state (an), the number of epidemic detection related staff (NRD), and the number of existing infections (NOI) according to the policy measures of the two people in epidemic prevention measures.

Table 1. Symbols for constructing the model.

\begin{tabular}{ccc}
\hline Serial number & Symbol & Description \\
\hline 1 & $\theta(k)$ & Stage ratio \\
2 & $R_{i}$ & Relative proportion \\
3 & $x^{(0)}(i)$ & Demand for labor \\
4 & $\lambda$ & Adjustment coefficient \\
5 & $\alpha$ & Development coefficient \\
6 & $\beta$ & Gray value \\
7 & $\omega$ & Correlation degree \\
8 & $\rho$ & Coefficient of variable \\
\hline
\end{tabular}

P.s: Other symbols instructions will be given in the text.

Table 2. Data on the period of the outbreak in the united states.

\begin{tabular}{ccccccc}
\hline Month & $\begin{array}{c}\text { Rate of } \\
\text { wearing masks }\end{array}$ & $\begin{array}{c}\text { Testing } \\
\text { price }\end{array}$ & $\begin{array}{c}\text { Testing } \\
\text { center }\end{array}$ & $\begin{array}{c}\text { Number of } \\
\text { employees }\end{array}$ & $\begin{array}{c}\text { Existing } \\
\text { infection }\end{array}$ & $\begin{array}{c}\text { New } \\
\text { infection }\end{array}$ \\
\hline Mar. & 0.07 & 1800 & 0.2 & 2034 & 1269 & 206,198 \\
Apr. & 0.08 & 2084 & 0.4 & 4258 & 206,267 & 919,038 \\
May. & 0.1 & 2376 & 1 & 7365 & $1,125,305$ & 696,812 \\
Jun. & 0.11 & 2246 & 1.2 & 12,356 & $1,822,117$ & 873,568 \\
Jul. & 0.13 & 2357 & 1.33 & 13,864 & $2,695,685$ & $1,959,926$ \\
Aug. & 0.15 & 2856 & 1.5 & 20,473 & $4,655,611$ & $1,521,596$ \\
Sept. & 0.17 & 3076 & 2 & 22,193 & $6,177,207$ & $1,236,393$ \\
Oct. & 0.18 & 2875 & 2.33 & 26,986 & $7,413,600$ & $1,812,958$ \\
Nov. & 0.2 & 2690 & 2.4 & 34,694 & $9,226,558$ & $3,751,775$ \\
\hline
\end{tabular}




\section{Choice of explained variables \\ New infections}

The data obtained are shown in Table 3.

\section{Choice of explanatory variables \\ Mask wearing rate (MSR)}

The rate of wearing masks reflects people's attention to the epidemic situation. When the first infected person appears, he does not wear a mask because he or she is not aware of the virus, and coughs and sneezes in communication with people, which eventually leads to human to human transmission of the virus. Therefore, it is particularly important to adhere to wearing masks to prevent the epidemic situation. Trump did not pay enough attention to the epidemic at the early stage of the outbreak and insisted on not wearing masks, while Biden supported the nationwide implementation of mandatory wearing masks. The data obtained are shown in Table 4.

\section{Average new crown test price (AP)}

The average price of new crown test can reflect the level of health care in the United States. Trump canceled the medical insurance policy, and Biden proposed to provide free new crown test for all Americans. The data obtained are shown in Table 5.

\section{Average number of testing centers per state (AN)}

The more health centers in the United States have adequate detection measures, and the more they have the average number of detection centers in each state, the more attention they have to the average number of detection centers. The data obtained are shown in Table 6.

\section{Number of employees related to epidemic detection (NRD)}

The number of staff related to epidemic monitoring reflects the total number of medical testing personnel invested in the epidemic situation in the United States. The more employees, the more stringent the prevention and control of the epidemic situation, and the speed of the spread of the epidemic will be reduced. The data obtained are shown in Table 7.

Table 3. Data on the number of new infections per month.

\begin{tabular}{cccccccccc}
\hline Month & Mar. & Apr. & May. & Jun. & Jul. & Aug. & Sept. & Oct. & Nov. \\
\hline \multirow{2}{*}{ New infections } & 206,198 & 919,038 & 696,812 & 873,568 & $1,959,926$ & \multirow{2}{*}{$1,521,596$} & $1,236,393$ & $1,812,958$ & $3,751,775$ \\
\hline
\end{tabular}

Table 4. Data on the rate of wearing masks per month.

\begin{tabular}{cccccccccc}
\hline Month & Mar. & Apr. & May. & Jun. & Jul. & Aug. & Sept. & Oct. & Nov. \\
\hline Rate of wearing masks & 0.07 & 0.08 & 0.1 & 0.11 & 0.13 & 0.15 & 0.17 & 0.18 & 0.2 \\
\hline
\end{tabular}

Table 5. Data on the Testing price per month.

\begin{tabular}{cccccccccc}
\hline Month & Mar. & Apr. & May. & Jun. & Jul. & Aug. & Sept. & Oct. & Nov. \\
\hline Testing price & 1800 & 2084 & 2376 & 2246 & 2357 & 2856 & 3076 & 2875 & 2690 \\
\hline
\end{tabular}




\section{Number of existing infections (NOI)}

The number of existing infections reflects the number of infected people in the United States during the epidemic period. If different preventive measures are taken, the number of existing infections will produce different results. If strict closed management is adopted, the rising speed of the existing infections will be greatly slowed down. If we take an indifferent attitude, the existing number of infections will increase explosively. The data obtained are shown in Table 8.

\section{b) Log linear model}

Based on the above analysis, we take the rate of wearing masks, the average price of new crown detection, the average number of detection points per state, the number of employees related to epidemic detection and the number of existing infections as explanatory variables, and the number of new infections as the explanatory variables. Considering that the heterosexuality should be weakened as much as possible, there is no strict linear relationship between the explanatory variables and the explained variables.

$$
\begin{aligned}
\ln \mathrm{NI}= & \ln \rho_{0}+\rho_{1} \ln \mathrm{MSR}+\rho_{2} \ln \mathrm{AP}+\rho_{3} \ln \mathrm{AN} \\
& +\rho_{4} \ln \mathrm{NRD}+\rho_{5} \ln \mathrm{NOI}
\end{aligned}
$$

Here $\ln \rho_{0}$ stands for a constant term, and a represents the random error term outside the model. $\rho_{1}, \rho_{2}, \rho_{3}, \rho_{4}, \rho_{5}$ respectively represent the elasticity of the corresponding explanatory variables.

\section{Model testing}

\section{Significance test}

We conducted a significant test on the regression results of the number of new infections. The results are shown in Table 9.

Table 6. Data on the Testing center per month.

\begin{tabular}{cccccccccc}
\hline Month & Mar. & Apr. & May. & Jun. & Jul. & Aug. & Sept. & Oct. & Nov. \\
\hline Testing center & 0.2 & 0.4 & 1 & 1.2 & 1.33 & 1.5 & 2 & 2.33 & 2.4 \\
\hline
\end{tabular}

Table 7. Data on the Number of employees per month.

\begin{tabular}{cccccccccc}
\hline Month & Mar. & Apr. & May. & Jun. & Jul. & Aug. & Sept. & Oct. & Nov. \\
\hline Number of employees & 2034 & 4258 & 7365 & 12,356 & 13,864 & 20,473 & 22,193 & 26,986 & 34,694 \\
\hline
\end{tabular}

Table 8. Data on the Number existing infections per month.

\begin{tabular}{cccccccccc}
\hline Month & Mar. & Apr. & May. & Jun. & Jul. & Aug. & Sept. & Oct. & Nov. \\
\hline Number of employees & 1269 & 206,267 & $1,125,305$ & $1,822,117$ & $2,695,685$ & $4,655,611$ & $6,177,207$ & $7,413,600$ & $9,226,558$ \\
\hline
\end{tabular}

Table 9. Results of significance test on the number of new infections.

\begin{tabular}{ccccc}
\hline Statistics & $\mathrm{R}^{2}$ & Adjusted $\mathrm{R}^{2}$ & Estimated standard error & Prob (F-statistic) \\
\hline Value & 0.947 & 0.923 & 0.264 & 0.009 \\
\hline
\end{tabular}


It can be seen from the above table that the goodness of fit of the logarithmic model is 0.767 , indicating that the linear relationship between the new infection and the explanatory variables after legalization is not strong. The Adjusted R2 of the model was 0.912 , indicating that about $91 \%$ of the new infections could be explained by explanatory variables, and the model had a good fitting degree. At the same time, the significance test value of the model is Prob (F-statistic) = 0.009 , less than 0.01 , so we can obviously deny the null hypothesis that the total regression coefficient is 0 .

Col-linearity test

We calculate the ovarian test of the regression model by calculating the variance expansion factor. The calculation results are shown in Table 10.

The V-if of NRD and noi are greater than 10, which indicates that the col-linearity hypothesis between explanatory variables of logarithmic model is tenable.

\section{Model improvement}

According to the above test, we omit the variables with large col-linearity: the number of staff in epidemic detection and the number of existing infections. The logarithmic linear model is established as follows:

$$
\ln \mathrm{NI}=\ln \hat{\rho}_{0}+\hat{\rho}_{1} \ln \mathrm{MSR}+\hat{\rho}_{2} \ln \mathrm{AP}+\hat{\rho}_{3} \ln \mathrm{AN}
$$

\section{Significance test:}

The significance test results of the new logarithmic model are shown in Table 11.

It can be seen from the above table that the goodness of fit of the logarithmic model is 0.977 , indicating that the linear relationship between the new infection and the explanatory variables after legalization is not strong. The Adjusted R2 of the model was 0.947 , indicating that about $95 \%$ of the new infections could be explained by explanatory variables, and the model had a good fitting degree. At the same time, the significance test value of the model is Prob (F-statistic) = 0.008 , less than 0.01 , so we can obviously deny the null hypothesis that the total regression coefficient is 0 .

Table 10. Results of significance test on the number of new infections.

\begin{tabular}{ccc}
\hline Character variable & Tolerance & VIF \\
\hline MSR & 0.109 & 9.196 \\
AP & 0.266 & 3.757 \\
AN & 0.749 & 1.334 \\
NRD & 0.087 & 22.992 \\
NOI & 0.074 & 35.674 \\
\hline
\end{tabular}

Table 11. Results of significance test for new logarithmic model.

\begin{tabular}{ccccc}
\hline Statistics & $\mathrm{R}^{2}$ & Adjusted $^{2}$ & Estimated standard error & Prob (F-statistic) \\
\hline Value & 0.977 & 0.913 & 0.017 & 0.008 \\
\hline
\end{tabular}




\section{c) Model prediction}

Based on the data of MSR, NP and Ni from March to November and the different policies of the two candidates, we respectively forecast the data of MSR, $\mathrm{NP}$ and NI in the next four months of the two policies. The results are shown in Table 12 below.

Based on the data of MSR, NP and NI under Trump and Biden policies and the established new logarithmic model, the number of new infections in the next four months under the two policies is predicted. The prediction results are shown in Figure 1 (Biden in red and Trump in blue).

\section{4) Result analysis}

From the forecast values of MSR, NP and Ni from November to March, we can see that Biden's efforts in prevention and control measures are unprecedented compared with Trump. Since the prediction of the number of infected people is based on the above three indicators to build a logarithmic linear model, Biden's advantage is also very obvious.

Table 12. Results of MSR, NP and NI forecasts in the next four months.

\begin{tabular}{ccccccc}
\hline \multirow{2}{*}{ Month } & \multicolumn{2}{c}{ Rate of wearing masks } & \multicolumn{2}{c}{ Testing price } & \multicolumn{2}{c}{ Testing Center } \\
\cline { 2 - 6 } & Trump & Biden & Trump & Biden & Trump & Biden \\
\hline Dec. & 0.235 & 0.275 & 2437 & 449 & 3.12 & 4.86 \\
Jan. & 0.258 & 0.587 & 2223 & 102 & 3.75 & 8.15 \\
Feb. & 0.326 & 0.647 & 2045 & 0 & 4.04 & 10.02 \\
Mar. & 0.357 & 0.702 & 1854 & 0 & 4.54 & 10.25 \\
\hline
\end{tabular}

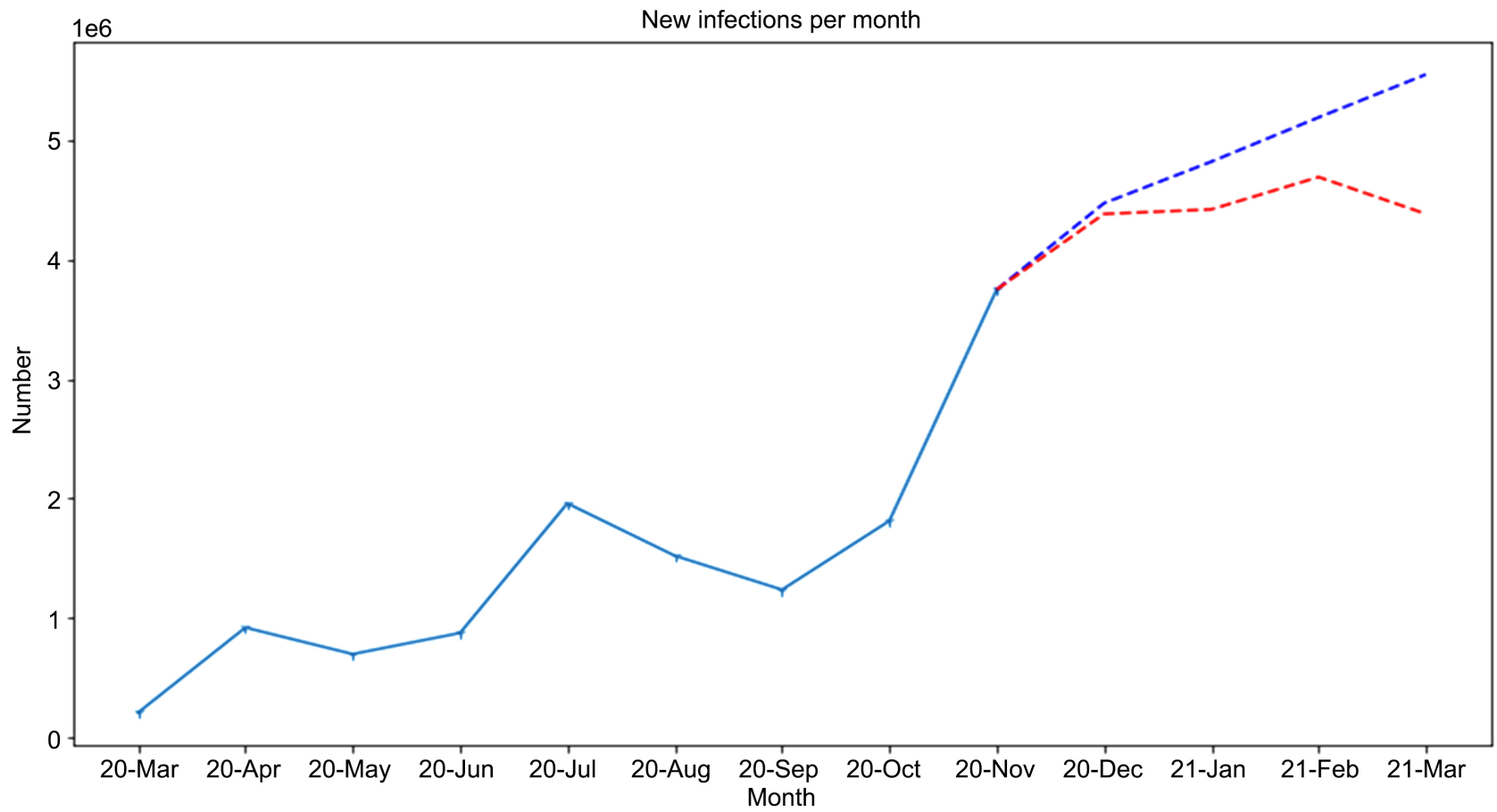

Figure 1. The trend chart of the number of new infections in the future under the two policies. 
This gap is not only a matter of leaders' policies. We need to see the attitude of the political parties behind the leaders

Democrats and Republicans are split on how to deal with the epidemic, according to a Pew Research Center poll released on October 8. 88\% of democratic respondents believe that the United States has failed to control the epidemic well, while only $30 \%$ of Republicans support this view. Sixty-six percent of Republicans said the epidemic was exaggerated. Compared with Democrats, Republicans are less willing to listen to the CDC's guidelines for Disease Control and prevention. Whether to wear masks has also become a "partisan" issue. Gallup's survey shows that $94 \%$ of Democrats always or often wear masks, while only $46 \%$ of Republicans are willing to do so. Obviously, differences and contradictions between politicians and voters from different parties in the United States are becoming increasingly fierce (Liu, 2020).

But at a time when the epidemic is raging, the United States must seek the greatest balance in the tension of controlling the epidemic and stimulating the economy. The novel corona-virus pneumonia will be the first economic priority for the US president, who will become the president of the United States.

However, the differences between the two parties on how to deal with economic problems under the epidemic situation are also very large. The Trump administration has been proud to boost the U.S. economy. However, the serious epidemic situation turned this achievement into "negative equity" in an instant. Therefore, under the background of the general election, how to use huge financial subsidies to stimulate the economy and which groups can benefit more from the fiscal stimulus plan has become the content of the fierce game between the Trump government and the house of Representatives controlled by the Democratic Party. Not long ago, Democrat and speaker of the house of Representatives Pelosi explicitly rejected the latest US $\$ 1.8$ trillion fiscal stimulus package proposed by the White House, saying that it failed to provide sufficient funds for the new crown test, worker safety protection, unemployment benefits, etc.

In short, behind the "epidemic politics" and other issues, we must see the profound evolution of American party politics and the multiple challenges that the American democratic system is facing.

\subsubsection{Impact of Medical Insurance}

This paper uses the data forecasting model with medical insurance policy to predict the proportion of medical expenditure in GDP in the next two years (2021-2022), which is used as the data under Biden policy (with medical insurance). Using the data forecasting model without medical insurance policy to predict the proportion of medical expenditure in GDP in the next two years (2021-2022), as the data under Trump policy (without medical insurance). Due to the lack of data, we establish a gray model for prediction.

\section{1) Data acquisition}

According to the comparison of Trump and Biden's different health care measures, some epidemic data collected will have an impact on the U.S. econo- 
my. We have decided to select the percentage of GDP medical expenditure (MEG), per ca-pita medical expenditure (AME), the percentage of out of Pocket Medical Care (SME) and the percentage of public health care (GME) in government expenditure (Zhu, 2020).

Percentage of GDP medical expenditure (MEG)

With the aggravation of aging and the increasing attention of residents to health, the percentage of GDP medical expenditure reflects the degree of national attention to medical care and reflects the quality of life of a country's population. If more money can be spent on effective prevention, it will be helpful to the quality of life and people's life extension. The data are shown in Table 13.

\section{Medical expenditure per ca-pita (AME)}

The per ca-pita medical expenditure is the ratio of the sum of public and private health expenditure and the total population, which can be used to measure the social and economic development degree of a country. The higher the value, the higher the development degree of the country. Trump canceled health care, while Biden offered free crown tests for all Americans. The data are shown in Table 14.

\section{Percentage out of pocket payments in personal care (SME)}

In the form of sharing medical expenses by medical insurance institutions and patients, the proportion of medical expenses allowed to be paid by the insured is stipulated in the medical insurance policy. The data are shown in Table 15.

Percentage of public health care in government expenditure (GME)

The percentage of public health care in government expenditure is used to measure the relationship between public resources consumed by health care services in a country or region and socio-economic output. The data are shown in Table 16.

Table 13. Data on the percentage of medical expenditure in recent ten years.

\begin{tabular}{ccccccccccccc}
\hline Year & 2010 & 2011 & 2012 & 2013 & 2014 & 2015 & 2016 & 2017 & 2018 & 2019 & 2020 \\
\hline MEG & 17.02 & 17.06 & 17.02 & 16.9 & 17.14 & 17.21 & 17.24 & 16.93 & 16.62 & 16.34 & 16.13 \\
\hline
\end{tabular}

Table 14. Data on the medical expenditure per ca-pita in recent ten years.

\begin{tabular}{ccccccccccccc}
\hline Year & 2010 & 2011 & 2012 & 2013 & 2014 & 2015 & 2016 & 2017 & 2018 & 2019 & 2020 \\
\hline AME & 8269 & 8523 & 8789 & 8987 & 9402 & 9612 & 9910 & 10,230 & 11,639 & 13,048 & 16,124 \\
\hline
\end{tabular}

Table 15. Data on the Percentage of out of pocket payments in personal care in recent ten years.

\begin{tabular}{cccccccccccc}
\hline Year & 2010 & 2011 & 2012 & 2013 & 2014 & 2015 & 2016 & 2017 & 2018 & 2019 & 2020 \\
\hline SME & 22.39 & 22.22 & 21.97 & 21.93 & 21.37 & 21.24 & 21.14 & 21.97 & 22.12 & 22.65 & 23.01 \\
\hline
\end{tabular}

Table 16. Data on the Percentage of public health care in government expenditure in recent ten years.

\begin{tabular}{ccccccccccccc}
\hline Year & 2010 & 2011 & 2012 & 2013 & 2014 & 2015 & 2016 & 2017 & 2018 & 2019 & 2020 \\
\hline GME & 18.97 & 19.46 & 20.08 & 20.78 & 21.29 & 21.54 & 21.92 & 20.89 & 20.45 & 20.18 & 20.07 \\
\hline
\end{tabular}




\section{2) Exploratory analysis \\ Description data}

Table 17 shows the average, standard deviation, minimum value, quarter digit, median, three quarters and maximum value of MEG, AME, SME and GME data under the two situations of whether the medical insurance policy exists or not.

As can be seen from Figure 2, the proportion of medical expenditure in GDP has increased year by year, and the per capita medical expenditure has been increasing. In 2010, the United States passed a new medical bill, which proposed to expand the coverage of medical insurance, establish the federal medical insurance exchange, regulate the management of the medical market, and implement the system of combining public medical insurance with commercial medical insurance, in which commercial medical insurance is the main one (Emery, 2009). The "patient protection and Affordable Care Act" mainly includes three aspects: first, expand the scope of medical insurance to cover every American; second, reduce the medical cost and solve the problem of "expensive medical treatment", which is very expensive in the United States. According to statistics, the average annual medical cost of each American is 7290 US dollars, accounting for $20 \%$ of the per capita income. It can be said that the burden is very heavy; third, it is necessary to reduce the medical cost and solve the problem of "expensive medical treatment" The main content is to improve the supervision of insurance companies to protect citizens with medical insurance. However, since Trump came to power in 2016, it is obvious that these graphs have had an obvious turning point in 2016. The percentage of medical expenditure in GDP has increased rapidly to about $17.2 \%$, and the per capita health care has also increased rapidly since 2016. The proportion of self paid personal medical care and the proportion of public health care in government expenditure have reversed the trend from 2010 to 2016, reaching the peak in 2016 and will not decline any more, On the contrary, it began to change in the opposite direction, which shows that 2016 is an important node. Because in 2016, Trump abolished

Table 17. Data analysis on the existence of medical insurance policy in two cases.

\begin{tabular}{|c|c|c|c|c|c|c|c|c|}
\hline & \multicolumn{2}{|c|}{ MEG } & \multicolumn{2}{|c|}{ AME } & \multicolumn{2}{|c|}{ SME } & \multicolumn{2}{|c|}{ GME } \\
\hline & Exist & Not Exist & Exist & Not Exist & Exist & Not Exist & Exist & Not Exist \\
\hline mean & 17.14 & 17.16 & 9204.55 & $13,604.21$ & 21.65 & 22.59 & 20.85 & 20.23 \\
\hline std & 0.07 & 0.02 & 526.64 & 2293.76 & 0.45 & 0.45 & 0.93 & 0.19 \\
\hline $\min$ & 17.06 & 17.14 & 8523.83 & $11,639.54$ & 21.14 & 22.12 & 19.46 & 20.07 \\
\hline $25 \%$ & 17.09 & 17.16 & 8839.31 & $12,343.9$ & 21.27 & 22.39 & 20.26 & 20.13 \\
\hline $50 \%$ & 17.13 & 17.17 & 9195.22 & $13,048.26$ & 21.65 & 22.65 & 21.04 & 20.18 \\
\hline $75 \%$ & 17.19 & 17.18 & 9559.95 & $14,586.56$ & 21.96 & 22.83 & 21.48 & 20.32 \\
\hline $\max$ & 17.24 & 17.18 & 9910.83 & $16,124.85$ & 22.22 & 23.01 & 21.92 & 20.45 \\
\hline
\end{tabular}



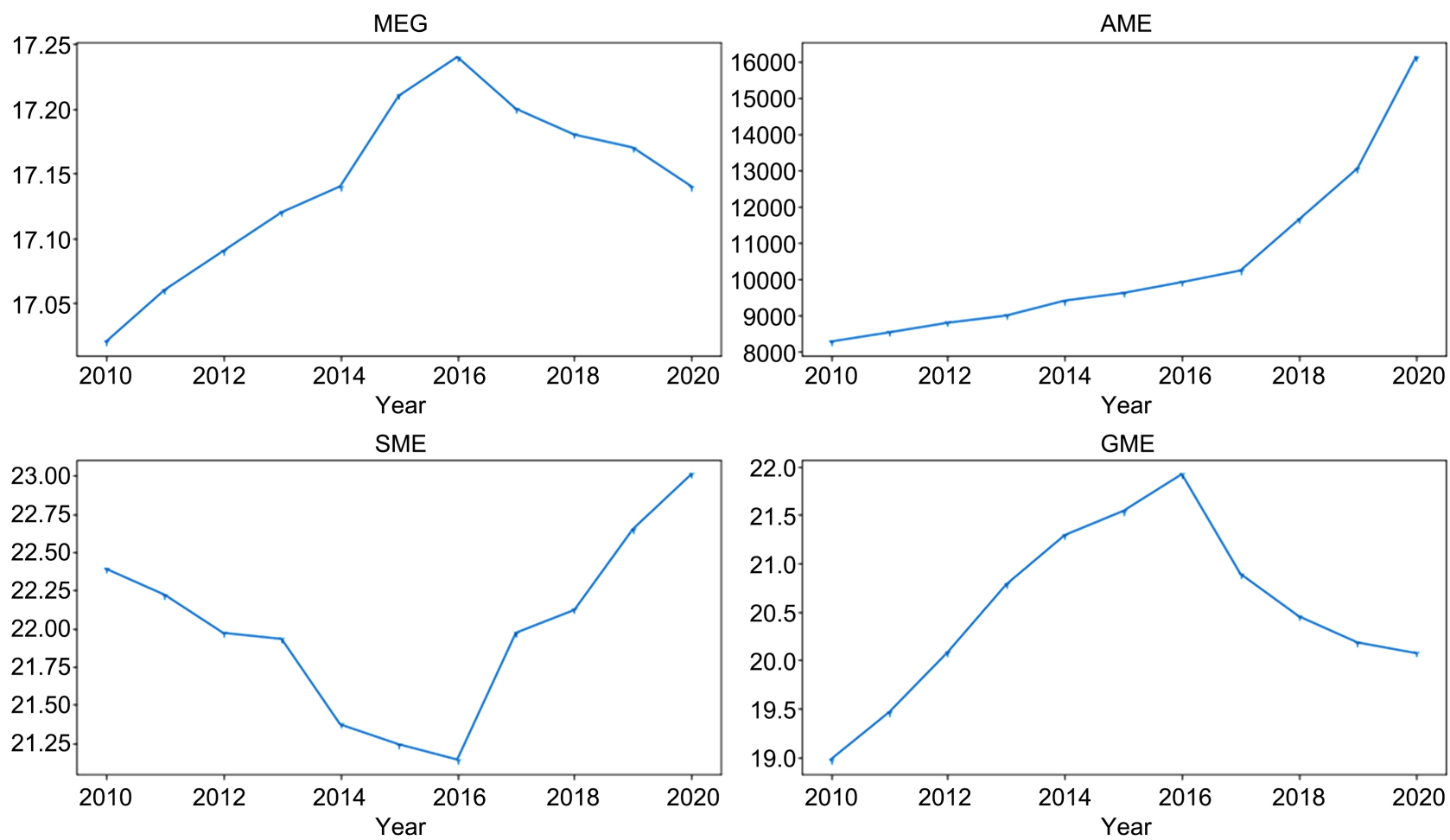

Figure 2. The trend of MEG, AME, SME, GME in recent ten years.

the health care reform plan. From the perspective of the government, the previous health care reform plan increased the financial expenditure of the United States, which would expand the government's fiscal deficit. The medical reform plan is essentially a macro-control of medical care by the government. This concept is emphasized by Trump this is the main reason for Trump's repeal of health care reform. Therefore, Trump has put forward his own medical insurance bill, which is beneficial to high-income people without previous medical history and enterprise employers, but it will have adverse effects on low-income people, elderly people and people with previous medical history. Contrary to Trump, Biden wants to restart the health insurance plan, not only to retain but also to expand the ACA, reduce the insurance premium rate, and reduce the increasingly heavy burden of health insurance on Americans.

\section{3) Level test}

We first need to test MEG data to determine its smoothness and usability. We find the sequence ratio by building MEG time series. Then we'll take the sequence level ratio. Then, we compare the sequence level ratio with the allowable coverage interval, and observe whether all the data fall into the interval, that is, whether the stability of the data meets the basic requirements of establishing the grey prediction system.

The MEG data with medical insurance policy are as follows:

$$
x^{(0)}=\left(x^{(0)}(1), x^{(0)}(2), x^{(0)}(3), \cdots, x^{(0)}(7)\right)=(17.02,17.06,17.09, \cdots, 17.24)
$$

Then the horizontal ratio of market demand is calculated according to the 
following formula:

$$
\theta(k)=\frac{x^{(0)}(k-1)}{x^{(0)}(k)}
$$

We calculated the data ratio:

$$
\theta(k)=(\theta(2), \theta(3), \cdots, \theta(7))=(0.813,1.172, \cdots, 0.845)
$$

In our judgment, if all ratios are within acceptable coverage $X=\left(e^{\frac{2}{n+1}}, e^{\frac{2}{n+1}}\right)$, Then GM $(1,1)$ model can be established by $x^{(0)}$ and gray prediction can be carried out.

Based on the data in this problem, we can calculate the tolerable coverage

$$
X=(0.947,1.056)
$$

After comparison, we found that most of the data are in this interval. Therefore, the stability of the original data meets the basic requirements of $\operatorname{GM}(1,1)$, and there is no need to process the original data.

\section{4) Model Building}

The GM $(1,1)$ model is effective and can be used for grey prediction. Firstly, the GM $(1,1)$ model establishes the data column through the use $x^{(0)}(i)^{\prime}$, and the specific form is as follows:

$$
x^{(0)}(i)^{\prime}+\alpha z^{(1)}(i)=\beta
$$

Here, $z^{(1)}(i)^{\prime}$ It's the background value of the white, $\beta$ The grey value reflects the change of data and the development coefficient reflects the development trend.

We can get it by substituting $i=2,3, \cdots, 36$ into the above formula

$$
\left\{\begin{array}{l}
x^{(0)}(2)^{\prime}+\alpha z^{(1)}(2)=\beta \\
x^{(0)}(3)^{\prime}+\alpha z^{(1)}(3)=\beta \\
\cdots \\
x^{(0)}(36)^{\prime}+\alpha z^{(1)}(36)=\beta
\end{array}\right.
$$

Then it represents the parameter vector to be estimated:

$$
u=\left[\begin{array}{c}
\alpha \\
\beta
\end{array}\right], Y=\left[\begin{array}{c}
x^{(0)}(2)^{\prime} \\
\cdots \\
x^{(0)}(36)^{\prime}
\end{array}\right], \quad B=\left[\begin{array}{c}
-z^{(1)}(2) \\
\cdots \\
-z^{(1)}(n)
\end{array}\right]
$$

Therefore, we can express the GM $(1,1)$ model as $Y=u B$, and then use the least square method to calculate the value of sum respectively. The corresponding whitening model is as follows:

$$
\frac{\mathrm{d} x^{(1)}(i)^{\prime}}{\mathrm{d} i}+\alpha x^{(1)}(i)=\beta
$$


We simplify it to the solution model:

$$
x^{(1)}(i)=\left(x^{(0)}(1)-\frac{\beta}{\alpha}\right) e^{-\alpha(i-1)}+\frac{\beta}{\alpha}
$$

According to the expression of the whitening model, the grey prediction equation can be obtained:

$$
x^{(1)}(k+1)^{e}=\left(x^{(0)}(1)-\frac{\beta}{\alpha}\right) e^{-\alpha k}+\frac{\beta}{\alpha}, k=1,2, \cdots, i-1
$$

The mathematical expression for converting the expression to the predicted value is as follows:

$$
x^{(0)}(k+1)^{e}=x^{(1)}(k+1)^{e}-x^{(1)}(k)^{e}, k=1,2, \cdots, i-1
$$

Finally, we use mat-lab to calculate the data according to the problem, and get the mathematical expression of the predicted value: (see Appendix for specific steps).

$$
x^{(1)}(k+1)=\left(x^{(0)}(1)\right) e^{-\alpha k}+\frac{\beta}{\alpha}=-308787 e^{-0.01817 k}+313461
$$

The Grey prediction model has a certain range of application, and the limit of development coefficient is:

1) When $-\alpha \leq 0.3$, GM $(1,1)$ model can make more accurate medium-term and long-term forecast.

2) When $0.3<-\alpha \leq 0.5$, GM $(1,1)$ model is more accurate in short-term forecast, and should be cautious in Medium-term Forecast.

3) When $0.5<-\alpha \leq 0.8, \operatorname{GM}(1,1)$ model was used to predict.

4) When $0.8<-\alpha \leq 1.0$, When GM $(1,1)$ model is used to forecast, it must be corrected.

5) When $-\alpha>1.0$, GM $(1,1)$ model cannot be used for prediction. In this problem, Because of $-\alpha=0.01817 \leq 0.3$, the model is also applicable to the short-term forecast of the team's 28 forecasts.

Next, taking the data from 2010 to 2016 as an example, the reliability of the calculated value of the prediction expression is tested. The results are shown in Table 18.

Table 18. Results of reliability test.

\begin{tabular}{ccccc}
\hline Year & MEG & Predictions & Relative error & Level ratio \\
\hline 2010 & 17.02 & 17.02 & 0 & 0 \\
2011 & 17.06 & 17.08 & $0.12 \%$ & 0.017 \\
2012 & 17.09 & 17.15 & $0.35 \%$ & -0.0085 \\
2013 & 17.12 & 17.1345 & $0.085 \%$ & 0.024 \\
2014 & 17.14 & 17.1467 & $0.039 \%$ & -0.054 \\
2015 & 17.21 & 17.22 & $0.058 \%$ & 0.084 \\
2016 & 17.24 & 17.2465 & $0.038 \%$ & 0.054 \\
\hline
\end{tabular}


It can be seen from the above table that the relative error and stage ratio deviation can be analyzed after the model is constructed to verify the effect of the model.

The results show that the maximum relative error of the model is $0.0035<0.1$, which means that the fitting effect of the model meets the higher requirements. For the stage ratio deviation value, if the value is less than 0.2 , it indicates that the requirements are met; if it is less than 0.1, it indicates that the requirements are met; the maximum value of model stage ratio deviation value is $0.084<0.1$, which means that the model fitting effect reaches the highest requirements.

\section{5) Model prediction}

Through this GM $(1,1)$ model, we can predict the MEG data of the United States in 2021 and 2022 with the medical insurance policy. Using the MEG data from 2017 to 2020, we can also predict the MEG data in 2021 and 2022 without medical insurance policy. As shown in Figure 3 (red for Biden, blue for Trump)

It can be seen from the figure that during Trump's administration, the percentage of medical expenditure (MEG) of GDP decreased year by year, and its predicted value is also in a downward trend, which is due to the change caused by Trump's repeal of Obama's medical insurance policy. Trump's political philosophy is more willing to shift more investment to the real economy. In Biden's prediction index, MEG is increasing year by year. That's because Biden, a fellow democratic politician with Obama, promised to restore the Obama care bill.

In the past, Obama care has made the popularity of medical insurance in the United States reach an unprecedented level, but at the same time it has touched the interests of the middle class, capitalists and insurance companies. It has been criticized by all walks of life for restricting market freedom and increasing financial burden. Trump's health care reform aims to replace Obama's, including abolishing compulsory insurance, changing subsidy mechanism and reforming Medicaid.

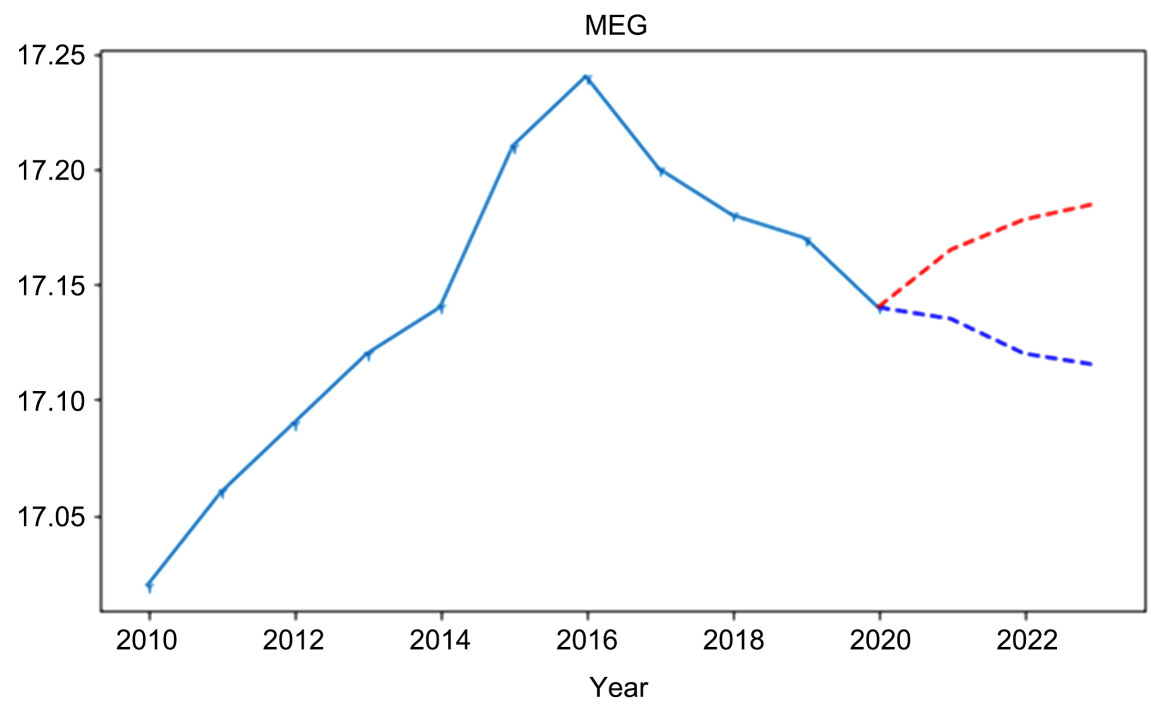

Figure 3. Data on MEG under the US health insurance policy in 2021 and 2022. 
There are various positive and negative comments on the different measures of the two kinds of health care reform. Trump's health care reform shows the ideological characteristics of the Republican Party and its individual market regulation and the priority of personal interests, and basically adjusts or even negates the contents of Obama's health care reform. Trump sees Medicare as more incommoded and reduces government spending on health care. These measures have lifted many restrictions on insurance companies during the $\mathrm{Ob}$ ama administration, and reduced the taxes that insurance companies should pay.

No matter Obama or Trump was in power, they all highly praised the managed medical care, which can be seen that it can improve the efficiency of social operation.

\subsection{Part 2: Impact on China}

\subsubsection{Impact on Stocks}

\section{1) Data acquisition}

The U.S. general election is in November, so we get the rise and fall of the Shanghai Composite Index from Ifind to November 2008-2020. The data obtained are shown in Table 19.

\section{2) Level test}

The rise and fall data of Shanghai composite index are as follows:

$$
s^{(0)}=\left(s^{(0)}(1), s^{(0)}(2), s^{(0)}(3), \cdots, s^{(0)}(13)\right)=(8.24,6.66,-5.33, \cdots, 5.7)
$$

Then, according to the following formula, we can calculate the horizontal ratio of the data of the rise and fall of the stock:

$$
\beta(k)=\frac{s^{(0)}(s-1)}{s^{(0)}(k)}
$$

We calculated the data ratio:

$$
\theta(k)=(\theta(2), \theta(3), \cdots, \theta(7))=(0.823,1.171, \cdots, 0.835)
$$

In our judgment, if all ratios are within acceptable coverage $S=\left(e^{-\frac{2}{n+1}}, e^{\frac{2}{n+1}}\right)$, GM $(1,1)$ model can be established by $s^{(0)}$ and gray prediction can be performed.

Based on the data in this problem, we can calculate the tolerable coverage.

$$
S=(0.95,1.24)
$$

We compare the data of the rise and fall of stocks with the time interval, and get Figure 4 .

Table 19. Data on the rise and fall of Shanghai Composite Index in recent 13 years.

\begin{tabular}{cccccccccccccc}
\hline Year & 2008 & 2009 & 2010 & 2011 & 2012 & 2013 & 2014 & 2015 & 2016 & 2017 & 2018 & 2019 & 2020 \\
\hline Up and down in Nov. & 8.24 & 6.66 & -5.33 & -5.46 & 4.29 & 3.68 & 2.85 & 1.86 & 4.82 & -2.24 & -0.56 & -1.95 & 5.7 \\
\hline
\end{tabular}




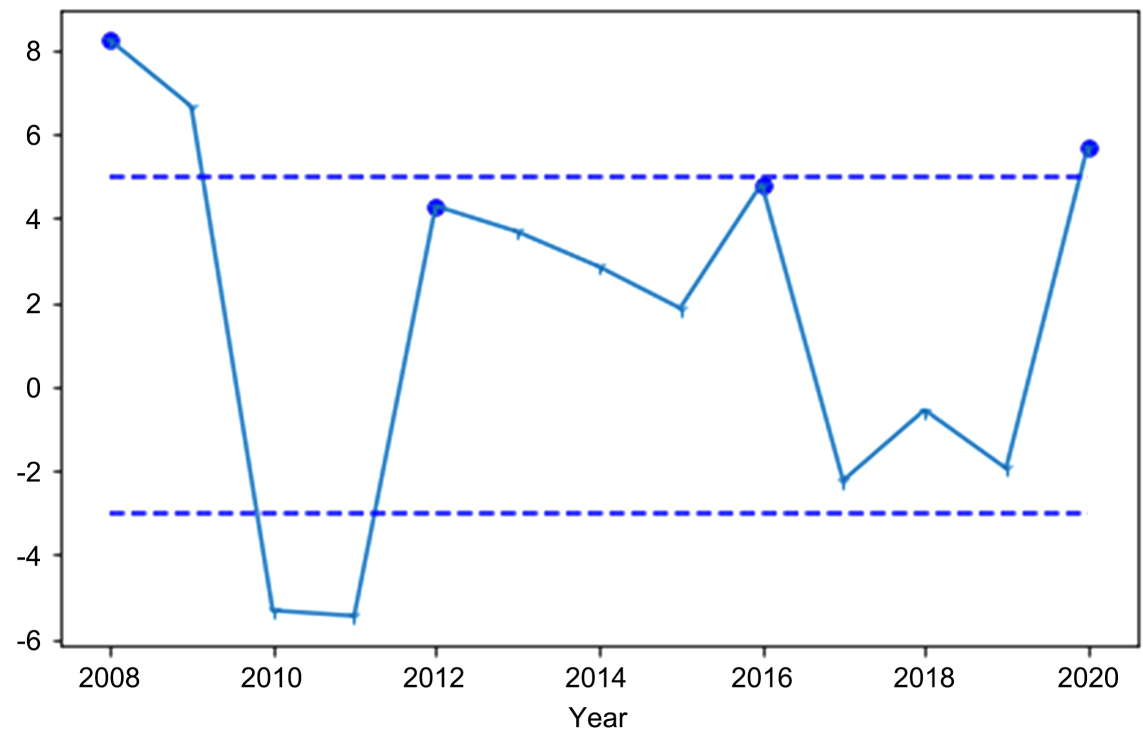

Figure 4. Chart of changes in stock price.

After comparison, we found that more data were not included in this interval. Therefore, the stability of the original data cannot meet the basic requirements of $\operatorname{GM}(1,1)$, so there is no need to process the original data.

\section{3) Eliminating seasonal factors}

We first calculate the moving average every four years. Since the period of moving average is even, we continue to use step 2 as step after moving average. After moving average correction $s^{(0)}(i)(=1,2, \cdots, 13$, which represents the rise and fall of the Shanghai Composite Index in November 2009 after two moving averages, and so on).

In order to obtain the weight ratio of each year, in other words, its importance in seasonal trends, this paper uses the size and direction of the data to change twice. We further calculate $R_{i}$, the relative ratio as follows:

$$
R_{i}=\frac{s^{(0)}(i)}{s^{(0)}(i)}(i=12,13,14, \cdots, 17)
$$

According to the above calculation formula, 24 Data $\mathrm{R}$ are obtained, and then the monthly average value is taken as the average value to obtain $W=\left[w_{1}, w_{2}, w_{3}, w_{4}\right]$, the seasonality index before adjustment from January to December. After calculation, we get the following results:

$$
\omega_{1}+\omega_{2}+\omega_{3}+\omega_{4}=3.452 \neq 4
$$

Therefore, the adjustment factor is considered in this paper, and the calculation formula is as follows:

$$
\lambda=\frac{12}{\sum_{\mathrm{k}=1}^{12} w_{k}}
$$

By multiplying the adjustment factor by the original season index matrix: 


$$
W^{\prime}=\left[w_{1}, w_{2}, w_{3}, w_{4}\right]\left[\begin{array}{l}
\lambda \\
\lambda \\
\ldots \\
\lambda
\end{array}\right]
$$

The new season index is $W^{\prime}=[0.1173,2.0067,2.7831,0.8249]$.

According to the new seasonal index, we calculate the time series of the rise and fall of the Shanghai Composite Index after eliminating the seasonal factors, as shown in Figure 5.

\section{4) Establishing grey model}

The calculation process is the same as the process of predicting medical insurance data in question 1 , so we will not repeat it. The reliability of the calculated value of the prediction expression was tested. The results are shown in Table 20.

It can be seen from the above table that the relative error and stage ratio deviation can be analyzed after the model is constructed to verify the effect of the model

The results show that the maximum relative error of the model is $0.00974<$ 0.1 , which means that the fitting effect of the model meets the higher requirements. For the stage ratio deviation value, if the value is less than 0.2 , it indicates that the requirements are met; if it is less than 0.1 , it indicates that the requirements are met; the maximum deviation value of model grade ratio is $0.086<0.1$, which means that the model fitting effect reaches the highest requirements.

\section{5) Forecast the rise and fall of stock in the future}

The forecast results of China's Shanghai Composite Index in 2021 and 2022 are shown in Figure 6 (the dotted line is the forecast value).

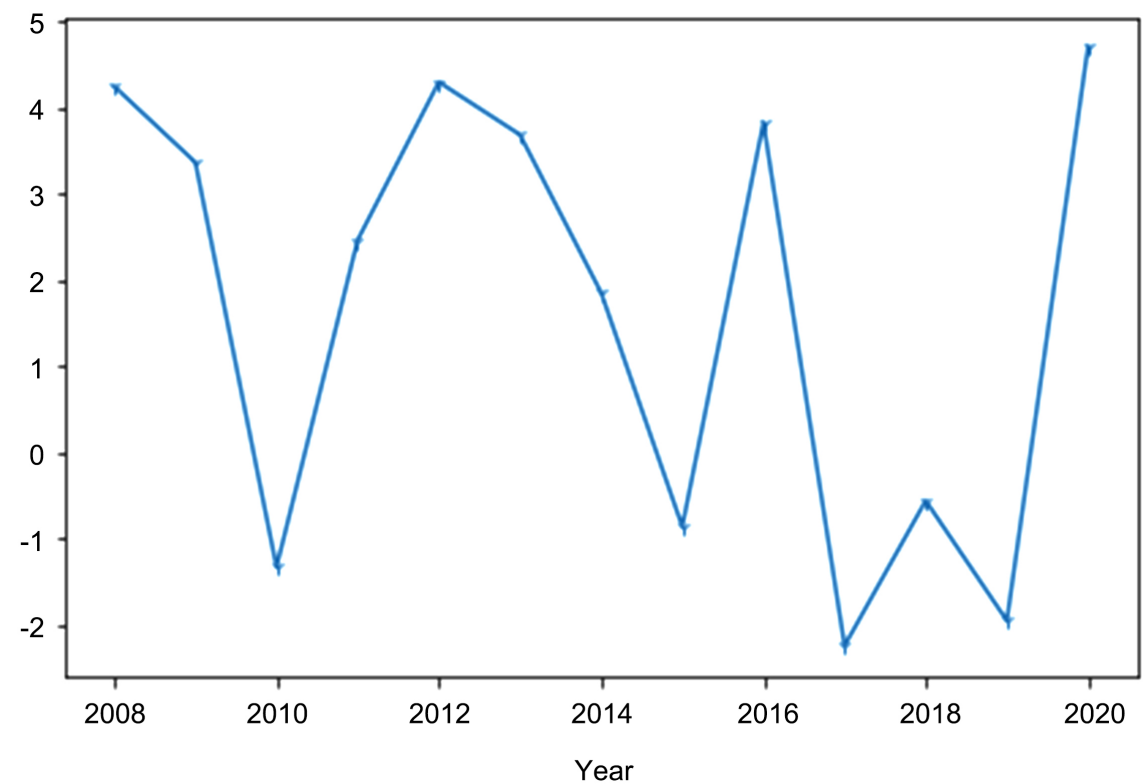

Figure 5. On the rise and fall of Shanghai composite index after eliminating seasonal factors. 
Table 20. Results of reliability test.

\begin{tabular}{ccccc}
\hline Year & Real & Predictions & Relative error & Level ratio \\
\hline 2008 & 5.24 & 5.24 & $0.00 \%$ & 0.00 \\
2009 & 4.36 & 4.54 & $-4.13 \%$ & -0.085 \\
2010 & -2.33 & -2.12 & $9.01 \%$ & 0.024 \\
2011 & -3.46 & -3.27 & $5.49 \%$ & -0.054 \\
2012 & 4.29 & 3.98 & $7.23 \%$ & 0.084 \\
2013 & 3.68 & 3.45 & $6.25 \%$ & 0.054 \\
2014 & 2.85 & 2.97 & $-4.21 \%$ & 0.043 \\
2015 & 1.86 & 2.04 & $-9.68 \%$ & -0.074 \\
2016 & 4.82 & 4.54 & $5.81 \%$ & 0.026 \\
2017 & -2.24 & -2.44 & $-8.93 \%$ & -0.083 \\
2018 & -0.56 & -0.52 & $7.14 \%$ & -0.036 \\
2019 & -1.95 & -1.76 & $9.74 \%$ & 0.067 \\
2020 & 4.7 & 4.55 & $3.19 \%$ & 0.086 \\
\hline
\end{tabular}

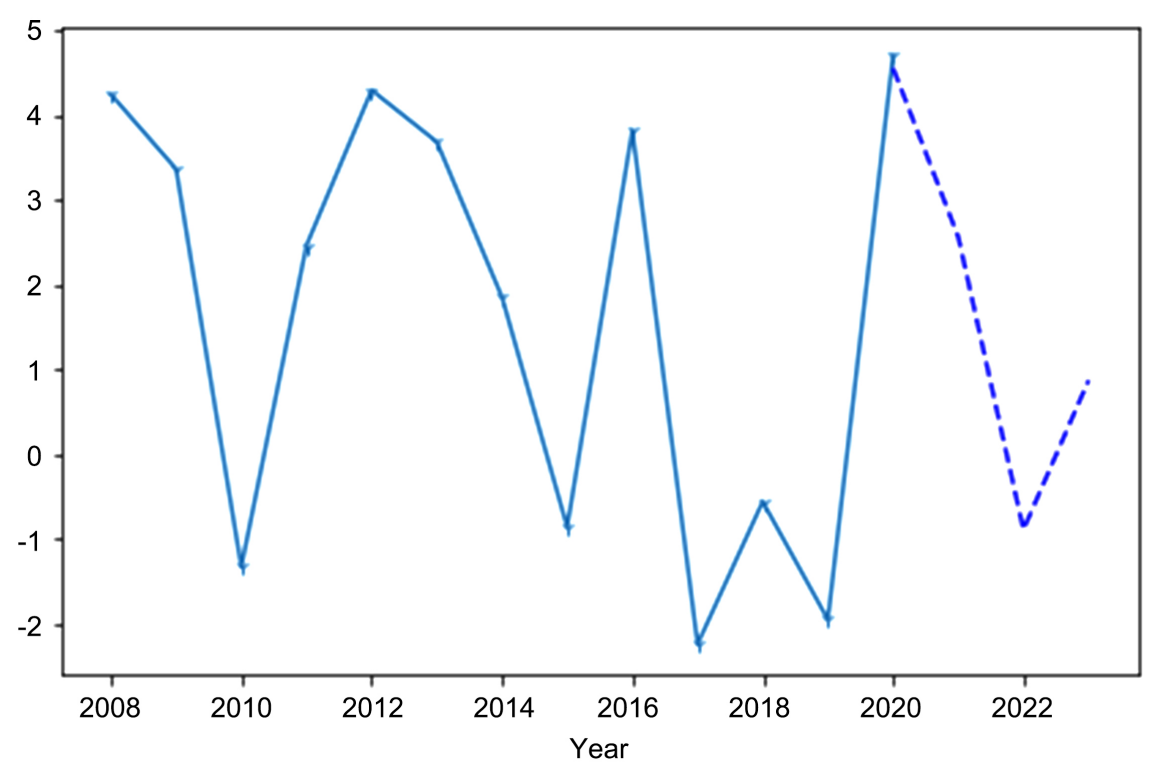

Figure 6. The results of the Shanghai composite index forecast.

\subsubsection{Impact on the Amount of Imports and Exports to the United States}

\section{1) Data acquisition}

We have obtained the quota of China's exports to the United States from 2008 to 2020 according to the statistics office of the United Nations. As shown in Table 21:

\section{2) Level test}

We calculated the data ratio:

$$
\mu(k)=(\mu(2), \cdots, \mu(11))=(1.023,1.071, \cdots, 1.135)
$$


Table 21. Data on China's export quota to the United States from 2008 to 2020.

\begin{tabular}{|c|c|c|c|c|c|c|c|c|c|c|c|c|}
\hline Year & 2008 & 2009 & 2010 & 2011 & 2012 & 2012 & 2014 & 2015 & 2016 & 2018 & 2018 & 2019 \\
\hline $\begin{array}{l}\text { Export volume } \\
\text { (US } \$ 100 \text { million) }\end{array}$ & 3636 & 3686 & 385 & 4256 & 4376 & 4538 & 4774 & 5058 & 5268 & 5314 & 5606 & 5994 \\
\hline
\end{tabular}

In our judgment, if all ratios are within acceptable coverage $P=\left(e^{-\frac{2}{n+1}}, e^{\frac{2}{n+1}}\right)$, GM $(1,1)$ model can be established by $\mu^{(0)}$ and gray prediction can be performed.

Based on the data in this problem, we can calculate the tolerable coverage:

$$
\mu=(0.95,1.24)
$$

After comparison, we found that more data were in this interval. Therefore, the stability of the original data can meet the basic requirements of $\operatorname{GM}(1,1)$, and there is no need to process the original data.

\section{3) Establish gray model}

The gray prediction model is established based on the data before and after Trump's administration. The calculation process of establishing gray model for the data before Trump's administration is the same as the process of predicting medical insurance data in question 1 , so we will not repeat it again. The reliability of the calculated value of the prediction expression was tested. The results are shown in Table 22.

It can be seen from the above table that the relative error and stage ratio deviation can be analyzed after the model is constructed to verify the effect of the model

The maximum relative error of the model is $0.0139<0.1$, which means that the fitting effect of the model meets the requirements. For the stage ratio deviation value, if the value is less than 0.2 , it indicates that the requirements are met; if it is less than 0.1 , it indicates that the requirements are met; the maximum value of model stage ratio deviation value is $0.174<0.1$, which means that the model fitting effect meets the requirements.

\section{4) Model prediction}

The prediction results of the model are shown in Figure 7.

According to the forecast value in the figure, in the short term, whether it is Trump or Biden in power, China's export volume is in a growth trend. However, in the long run, the forecast of China's export volume during Trump's administration showed a downward trend, while that of Biden was good.

Indeed, during Trump's presidency, his unpredictable attitude made Sino US relations worse and worse. In particular, the US side has always been unpredictable in the Sino US trade negotiations and reneged, which eventually led to more and more frustrations in Sino US trade. If Biden is in power, it will reduce the possibility of irreparable disastrous conflict between China and the United States, and his foreign policy will return to the traditional American line. 
Table 22. Results of reliability test.

\begin{tabular}{ccccc}
\hline Year & Real & Predictions & Relative error & Level ratio \\
\hline 2008 & 3636 & 3636 & $0.00 \%$ & 0.00 \\
2009 & 3686 & 3713 & $-0.73 \%$ & -0.125 \\
2010 & 3854 & 3807 & $1.32 \%$ & 0.114 \\
2011 & 4256 & 4197 & $1.39 \%$ & -0.153 \\
2012 & 4376 & 4318 & $1.33 \%$ & 0.144 \\
2013 & 4538 & 4601 & $-1.39 \%$ & 0.054 \\
2014 & 4774 & 4754 & $0.42 \%$ & 0.043 \\
2015 & 5058 & 5123 & $-1.29 \%$ & -0.174 \\
2016 & 5268 & 5203 & $1.23 \%$ & 0.026 \\
\hline
\end{tabular}

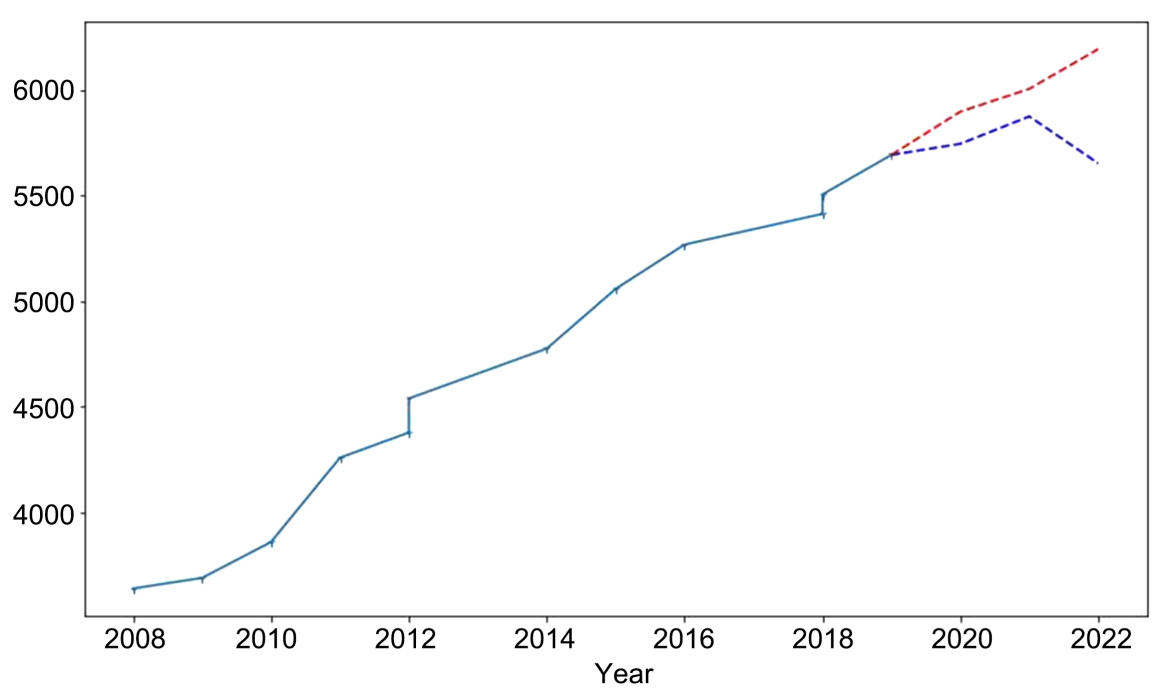

Figure 7. Trend chart of future US economic forecasts.

According to a recent survey conducted by the American Chamber of Commerce in Shanghai, most American enterprises in China welcomed Biden's announcement as "President-elect" by American media. They believed that Biden's government would bring more stability to Sino US relations. In terms of politics and revenue, the business prospects of American enterprises in China are more optimistic.

Biden once said in his speech that "the Sino US problem does not lie in the trade deficit". Biden supports free trade, returns to multilateralism and opposes tariffs. Therefore, it can be inferred that the future Sino US economic and trade will be more of a competition of "Global trade rules and competitiveness", and the "tariff war" and "trade war" in the Trump era will become history. However, the two parties of the United States have reached a strong consensus on China. Biden's attitude towards China has changed from mild to tough, and it is possible to unite with the allies to check and balance China (Wang, Dong, Zhang, Ji, \& An, 2020). 
However, we will not give up any opportunity to improve Sino US relations. In the future, China and the United States should keep sober headed and strategic determination, and exercise restraint and containment. The world also hopes Biden will be an enlightened, open and new US president who supports globalization. Cooperation between China and the United States will benefit both sides, while fighting will hurt both!

\section{Part 3: Suggestions for China}

We combine the models of the first two part with the hot topic of "American election" to carry out data mining. The results of the prediction are displayed in the form of word cloud.

\subsection{The Construction of Word Cloud Picture}

The steps of visualization are as follows:

1) In the whole network topics and models, get the content of words,

2) Obtain the mask map of the content display area;

3) Call wordcloud library to display the word cloud.

The results of data mining prediction are visualized and displayed in the form of word cloud graph to meet the needs of human-computer interaction of big data analysis platform. [intelligent campus implicit user behavior data mining method Chen Wanzhi, Zhao Yuxuan] in the visualization process, not only static information is displayed, but also dynamic information is divided.

The thematic portraits are of certain practical significance for us to give China's development suggestions from the perspective of economic development think tank members. See Figure 8.

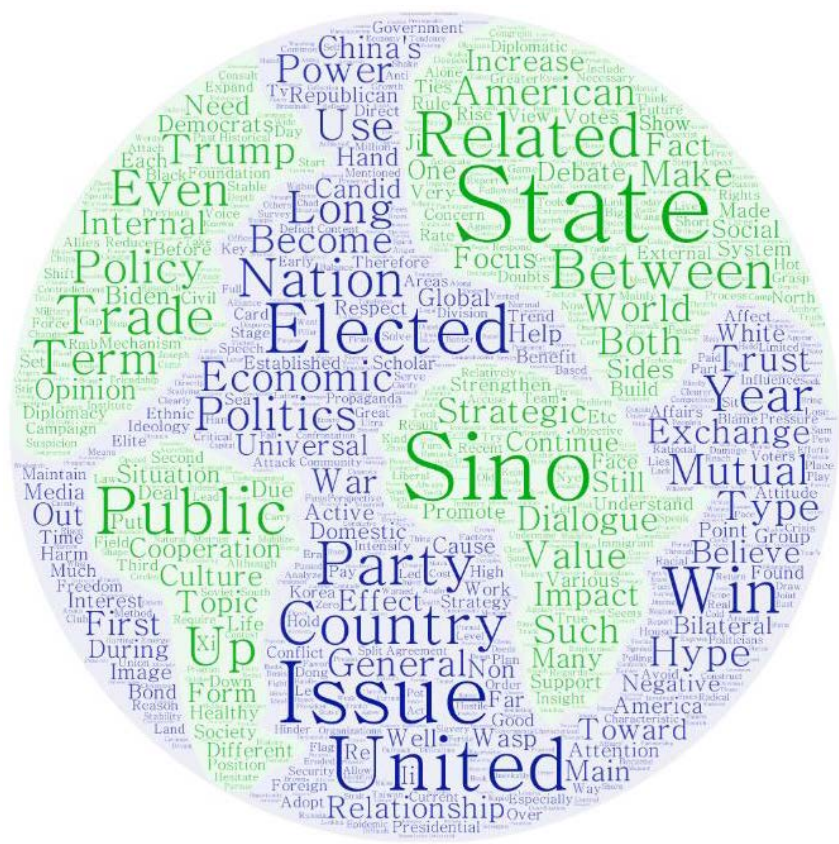

Figure 8. Visual display of topic keywords. 


\subsection{Word Frequency Analysis}

According to the word frequency chart, the top five proper nouns in the whole topic are: economic relations, trade relations, Sino US trade war, chip and trade mode. Obviously, these are all hot words about the theme of "American election".

Among them, the word chip can be used as a central word to connect the remaining proper terms: we know that under the Sino US trade war, the most heated and controversial issue is the chip issue (Tang, 2020).

The domestic chip companies, which have experienced the test of life and death, have come to a clear mind in the past two years and have seen the general direction of Chinese chips (Wang et al., 2020). For the future of Chinese chips, there are four big words in everyone's heart: domestic substitution. In such a global chip competition pattern, if China wants to make chips independently controllable, it must have the ability of independent research and development and production core force. Huawei's experience tells us that core technology can't be bought back with much money (Wang, 2020).

Despite the rapid development of China's science and technology, we still have to admit that there are still many technologies lagging behind, especially in the field of chips, which is widely concerned, and this is the weakness of China. The reason is that China developed late in the chip field, so the progress of China's chip technology is relatively slow, and it is difficult to reverse in the short term (Zhou \& Qin, 2020).

At present, the core technology in the world is chip, which is the most important component of modern technology. However, the chip industry is a very complex industry, which involves many fields, such as integrated circuits, optoelectronic devices and sensors. It also relates to the industry chain of chip materials, design software, chip design and production packaging. Therefore, if we need to develop chips, we must make breakthroughs and progress in many industries, otherwise the chip industry will only stop. Facing the problem of chip shortage, Huawei resolutely decided to survive by selling the glory mobile phone business. In this way, Huawei can get a short-term relief, strive to break through the limitations of American technology, design and manufacture real domestic chips.

In the process of chip manufacturing, $\mathrm{R} \& \mathrm{D}$ and innovation is not the most difficult thing for Chinese enterprises. The most important thing is that they can not use American technology, which means that there are mature technologies that can not be used and have to be shelved. Therefore, Chinese enterprises need to develop new chip manufacturing technology by themselves. However, the development of China's chip manufacturing industry has been stopped for many years, but now it is restricted by this, which seriously restricts the chip industry and many related industries in China. According to customs statistics, the purchase amount of memory chips in China will reach 105.9 billion US dollars in 2019. Even under such a large volume, foreign chip manufacturers still keep 
looking for price increases, but we can only accept it because we do not have our own chip industry.

\subsection{Conclusion and Suggestion}

We decided to give priority to "chip", combining the model of the first two questions and network data, we can draw the following conclusions and suggestions:

Gives the human by the fish him to fish.

1) With the gathering of outstanding talents as the strategic cornerstone accelerates the formation of a high-level technical talent team.

The foundation of gathering excellent talents lies in education, only education is the foundation of building talents. Colleges and universities should attach importance to the development of disciplines related to chip industry and provide high-tech talents for related industries. At the same time, the relevant industries should also appropriately improve the treatment to retain talents who have the idea of leaving.

2) We should accelerate the formation of subversive and innovative scientific research achievements with the strategic guidance of major national projects;

The government can publish strategic guidelines in the chip related industries and give sufficient capital space to guide the development of the industry.

3) Enterprises seek breakthrough from themselves, and enterprises with market are good enterprises.

As we all know, chip is not only a "high-end" technology industry, but also a highly market-oriented industry, which means that only products and enterprises that can meet the market demand can stay to gain a share in the chip market means to control the right to speak. As for the entrepreneurial team that has just come out of the laboratory and scientific research institute, the capital is in short supply, and the technology is difficult to transfer to the ground, so it is necessary to work steadily.

Giving systematic guidance:

1) The government uses macro-control measures to increase investment in economic resources for chips.

The government should support the achievement transformation and implementation of design enterprises, and support key enterprises to step up the layout in the emerging field of $5 \mathrm{G}$ and play a leading role.

2) It is to accelerate the formation of a world-class chip industry innovation economic belt with the strategic support of innovation platform cluster, further to improve the system and mechanism of scientific and technological innovation, optimize the environment, gather resources, increase R \& D efforts, seize the opportunity of future development, and strive to build a world-class integrated circuit design industrial park.

3) Social organizations should give great support to the industry and encourage social funds to invest in the industry. 
In recent years, Zhongguancun IC Design Park has joined hands with ICC to launch the core innovation space with the operation philosophy of "light asset, strong service". For the integrated circuit industry, we will build a characteristic incubation service system to provide high-value and customized services for enterprises, and achieve the goal of growing together with the park and the project, and win-win between enterprises and the incubation platform.

\section{Lifting restrictions and relaxing development:}

1) Strengthen government procurement and relax export restrictions, maintain and expand the chip market.

The state can implement a series of policies to stimulate domestic demand and promote the market expansion of the chip industry to attract funds into the market.

2) We should relax the anti-monopoly control on Cooperative Innovation in the chip industry, and promote joint innovation and joint venture merger and acquisition of chip enterprises.

The government can temporarilyy relax the relevant regulatory measures to give the industry a certain growth space.

3) The chip industry is a global and open system. We should adhere to the mindset of cooperation, openness and win-win. Core creates the space of globalization, the principle of open cooperation, make full use of global resources, from the market, capital, talent, technology, such as multiple levels, deepen international cooperation: to reach a friendly cooperation with multiple chip technology power, as well as exchange, promote the development of industrial chain each link open innovation, hard into the global IC industry ecology system.

Finally, I would like to say that China should unswervingly open up wider to the outside world, actively integrate into the global value chain, adhere to multilateralism and economic globalization, shoulder its responsibilities as a major country, and be a promoter of regional economic cooperation. While developing its own economy, China should drive the steady and sound development of the regional and world economy.

\section{Conflicts of Interest}

The authors declare no conflicts of interest regarding the publication of this paper.

\section{References}

Emery, J. C. H. (2009). Origins of American Health Insurance: A History of Industrial Sickness Funds. Bulletin of the History of Medicine, 83, 623-625. https://doi.org/10.1353/bhm.0.0238

Li, H., \& Chen, Y. H. (2020). Review of Foreign Scholars' Research on Sino US Trade War. School Party Building and Ideological Education, No. 18, 90-93.

Liu, F. (2020). The Impact of the New Epidemic on the Health Care System in the United States. Banker, No. 8, 75-77. 
Tang, K. M. (2020). Historical and Realistic Causes of Sino US Trade War. Commercial Economy, No. 8, 49-51.

Wang, C. (2020). An Empirical Analysis on the Revival of Semiconductor Chip Technology Industry in the 1990s. Cyberspace Security, 11, 100-105.

Wang, D., Dong, C. L., Zhang, Z. X., Ji, C., \& An, G. (2020). The Election Results Will Not Change the Tone of the US China Policy with Competition as the Main Factor. Round Table Interview on "the 2020 US Election and Sino US Relations". World knowledge, No. 14, 19-23.

Zhou, R. Q., \& Qin, S. Y. (2020). A Critical Discourse Analysis of News Reports on Sino-US Trade War in The New York Times. English Language Teaching, 13, 85-98. https://doi.org/10.5539/elt.v13n10p85

Zhu, X. L. (2019). Experience and Enlightenment of Medical Insurance Payment Reform Based on Integrated Medical Services in the United States. Chinese Prices, No. 1, 89-91. 